\title{
Nutritional regulation of milk fatty acid composition
}

\author{
Kevin J. Shingfield \\ Animal Production Research, MTT Agrifood Research,31600 Jokioinen, kevin.shingfield@mtt.fi
}

\begin{abstract}
There is increasing evidence that nutrition plays an important role in the development of chronic diseases in the human population including cancer, cardiovascular disease, insulin resistance and obesity. Developing foods that enhance human health is central to dietary approaches for preventing and reducing the economic and social impact of chronic disease. Numerous studies in human subjects have implicated a high consumption of medium-chain (12:0-16:0) saturated fatty acids (SFA) and trans fatty acids (TFA) as risk factors for cardiovascular disease risk, with emerging evidence of a possible role in the development of insulin resistance and inflammation. Milk and dairy products are a major source of 12:0, 14:0, 16:0 and TFA in the human diet. However, developing public health policies promoting a decrease in milk, cheese and butter consumption ignores the value of these foods as a versatile source of nutrients and bioactive lipids, including 4:0, branch-chain fatty acids, cis-9, trans-11 conjugated linoleic acid (CLA), vitamins A and $\mathrm{D}, \beta$-carotene and sphingomyelin. Therefore, altering milk fatty acid composition through sustainable, environmental and welfare acceptable means is an integral component of an overall strategy for preventing human chronic disease. Nutrition is the major environmental factor regulating milk fat composition. Strategies for enhancing the nutritional value of milk fat have been directed towards reducing the proportion of 12:0, 14:0 and 16:0, increasing cis monounsaturated fatty acids (MUFA) and polyunsaturated fatty acid (PUFA) content and/or enhancing the concentration of bioactive lipids. Formulation of diets to alter milk fat composition to meet these targets typically involves 1) inclusion of plant oils and oilseeds, 2) supplements of marine lipids, 3) increasing the proportion of dietary energy derived from fresh grass, 4) replacing ensiled grass, maize or whole-crop cereal with forage legumes or 5) inclusion of rumen-protected lipids in the diet. Nutritional strategies for reducing 12:0, 14:0 and 16:0 and enhancing cis-MUFA in milk fat are dependent on increasing the supply of $\mathrm{C}_{18}$ or longer-chain fatty acids to inhibit mammary de novo fatty acid synthesis. Due to incomplete metabolism of dietary unsaturated fatty acids in the rumen, inclusion of oils or oilseeds in the diet also increases milk fat TFA content. Both the concentration and distribution of TFA isomers in milk is dependent on the amount and type of lipid supplement fed, composition of the basal diet and interactions between these factors. Altering the diet of lactating cows can be used as a means to significantly enrich milk fat cis-9, trans-11 CLA content. Increases in the concentration of CLA in milk are reliant, in the most part, on enhancing ruminal trans-11 18:1 outflow for endogenous cis-9, trans-11 CLA synthesis in the mammary gland. The potential to increase $n-3$ fatty acids in milk is relatively limited. Inclusion of fresh or ensiled red clover in the ruminant diet significantly increases 18:3 n-3 content, while increases in milk 20:5 n-3 and 22:6n-3 concentrations to marine lipid supplements is relatively limited due to extensive ruminal metabolism of $n-3$ PUFA. Greater enrichment of 20:5 n-3, 22:5 n-3 and 22:6n-3 in milk can be achieved using rumen-protected fish oil supplements. Overall, recent research has highlighted the important role of nutrition in attempts to modify milk fat composition for improved long-term human health.
\end{abstract}

Key Words: human health, milk fat, saturated fatty acids, trans fatty acids, conjugated linoleic acid 


\section{Background}

During the past decades there has been increased awareness of the association between diet and health, which has led to nutritional quality becoming an increasing important determinant of consumer food choices. A major development has been the recognition that lipids in the diet can affect health maintenance and disease prevention. Numerous studies in human subjects have implicated a high consumption of saturated fatty acids (SFA) and trans fatty acids (TFA) as risk factors for cardiovascular disease risk, with evidence that high SFA intakes may also be related to lowered insulin sensitivity which is a key factor in the development of the metabolic syndrome. Whilst it is generally accepted that SFA raise plasma total and low-density lipoprotein (LDL) cholesterol concentrations, atherogenic effects are considered to be confined to 12:0, 14:0 and 16:0 (Givens \& Shingfield, 2006). Based on evidence from epidemiological and intervention studies, national health policies developed to reduce the incidence of chronic disease risk have recommended a population-wide reduction in the intake of total fat, SFA and TFA. More recently, changes in legislation on the nutritional labelling of foods have been implemented in several countries, including Denmark, Canada and the United States with the sole purpose of reducing TFA in the human diet. It is probable that declarations on the trans fat content of foods will become mandatory for all EU countries in the future.

Developing foods that enhance human health is central to dietary approaches for preventing and reducing the economic and social impact of chronic diseases, including cancer, cardiovascular disease, insulin resistance and obesity. Milk and dairy products are the major source of 12:0 and 14:0 in the human diet and also make a significant contribution to 16:0 and TFA intake. However, developing public health policies promoting a decrease in milk, cheese and butter consumption ignores the value of these foods as a versatile source of nutrients. Furthermore, consumption of milk and dairy products may confer beneficial effects with respect to the prevention of osteoporosis, cancer, atherosclerosis and other degenerative disorders (Shingfield et al., 2008). A number of minerals, proteins, peptides and lipids in milk and fermented dairy products exhibit bioactive properties with the potential to improve long-term human health (Parodi, 2001; Korhonen \& Pihlanto, 2006). Milk fat contains a number of components including 4:0, branch-chain fatty acids, trans-11 18:1, cis-9, trans-11 conjugated linoleic acid (CLA), trans-9, trans11 18:2 CLA, vitamins A and D, $\beta$-carotene and sphingomyelin that have been shown to elicit antimutagenic properties in a number of biomedical studies (Parodi, 2001; Bauman et al., 2005; Shingfield et al., 2008).

Nutritional modification of milk fatty acid composition through sustainable, environmental and welfare acceptable means could be used as an integral component of an overall strategy for populationwide disease prevention. In the following sections, an overview of the metabolic origins of milk fatty acids and recent evidence on the potential of altering milk fat composition through nutritional means for improving long-term human health is considered.

\section{Metabolic origins of milk lipids}

In order to develop effective nutritional strategies for altering the concentration of specific fatty acids in milk fat the metabolic origins of these compounds has to be considered. Bovine milk typically contains between 3-5\% fat depending on diet and genotype (Givens \& Shingfield, 2006). Lipids in milk are secreted as globules emulsified in the aqueous phase and contain nonpolar core lipids mainly as triacylglycerides (TAG; $96-98 \%$ of total milk lipids) with small amounts of cholesteryl esters $(0.02 \%)$, non-esterified fatty acids (NEFA; 0.22\%) and retinol esters (Jensen, 2002). Milk fat globules are surrounded by a membrane comprised of phopholipids, cholesterol, and cholesterol esters. Even though there is enormous diversity in the profile of fatty acids in milk with more than 400 specific isomers reported (Jensen, 2002), the major fatty acids in milk fat TAG include 4:0-18:0, 16:1 cis-9, 18:1 cis-9, trans 18:1 and 18:2 n-6 (Givens \& Shingfield, 2006).

Fatty acids incorporated into milk fat TAG are derived from two sources, mammary de novo synthesis and the uptake of preformed fatty acids from peripheral circulation. Direct uptake typically contributes to about $60 \%$ of total fatty acid secretion in milk fat (Chilliard et al., 2000). Both acetate and $\beta$-hydroxybutyrate derived from organic matter digestion in the rumen are used by mammary epithelial 
cells to synthesize short- and medium-chain fatty acids. Mammary de novo synthesis accounts for all 4:0 to $12: 0$, most of the 14:0 (circa 95\%) and about 50\% of $16: 0$ secreted in milk, while all 18 carbon and longer chain fatty acids are derived entirely from circulating plasma lipids (Lock \& Shingfield, 2004).

Following intestinal absorption, long chain fatty acids are transported to the mammary gland in plasma in the form of NEFA and TAG-rich chylomicrons and very low-density lipoproteins (VLDL) (Chilliard et al., 2000). Mammary uptake of low and high-density lipoproteins is limited, and only thought to be a significant source of fatty acids at high arterial concentrations. Fractional removal rate of fatty acids from plasma TAG circulating in VLDL and chylomicra is known to be very rapid compared with the remaining LDL fraction in lactating cows (Palmquist et al., 1976), with estimates that around $70 \%$ of plasma TAG are hydrolyzed during the passage of blood through the mammary gland, with the fatty acids released being available for milk fat synthesis. Mammary uptake of 16:0 and all longer fatty acids are derived from the absorption of fatty acids in the small intestine and during mobilisation of tissue adipose. Absorbed fatty acids derived from the diet, microbial fatty acid synthesis in the rumen and endogenous lipids are used for the assembly of TAG in the intestinal epithelium and transported as plasma chylomicrons and VLDL. Long-chain fatty acids taken up by the mammary gland are obtained from the TAG fractions of circulating VLDL and chylomicrons via the action of mammary lipoprotein lipase. Fatty acids incorporated into cholesterol esters and phospholipids and transported in plasma mainly as highdensity lipoproteins that are relatively poor substrates for lipoprotein lipase. Even though plasma TAG and NEFA represent less than $3 \%$ of total plasma lipids these sources contribute to about $60 \%$ of fatty acids secreted in milk (Chilliard et al., 2000).

De novo fatty acid synthesis has an absolute requirement for acetyl-CoA, two key enzymes (acetyl-CoA carboxylase and fatty acid synthetase) and a supply of NADPH reducing equivalents (refer to Lock \& Shingfield, 2004). Acetate, and to a lesser extent $\beta$-hydroxybutyrate, contribute to the initial four carbons units required for fatty acid synthesis. Acetate is converted to acetyl Co A in the cytosol and incorporated into FA via the malonyl-Co A pathway, whereas $\beta$-hydroxybutyrate is incorporated directly following activation to butyl Co A. Conversion of acetate to acetyl-CoA via acetyl-CoA carboxylase is considered to be the rate-limiting step. Fatty acid synthetase consists of a large enzyme complex and is responsible for chain elongation. Acetyl, butyl and malonyl-Co A condense within the fatty acid synthetase complex and chain elongation occurs through continual loading of additional malonyl-Co A groups. A distinctive feature of the bovine mammary gland is its ability to release fatty acids from the synthetase complex at various stages, resulting in the secretion of a wide range of short and medium chain fatty acids. It is now well established that increases in the supply of long chain fatty acids to the mammary gland inhibits the synthesis of short and medium chained saturates (Chilliard et al., 2000).

Mammary gland epithelial cells contain the $\Delta-9$ desaturase complex that is responsible for catalyzing the oxidation of fatty acyl CoA esters which results in the introduction of a cis double bond between carbon atoms 9 and 10. Palmitoyl- and stearoyl-CoA are the preferred substrates for $\Delta-9$ desaturase leading to the formation of palmitoleoyl- and oleoyl-CoA, respectively (Palmquist et al., 2005). Activity of $\Delta-9$ desaturase in the mammary gland of ruminants is thought to occur as a mechanism to maintain and regulate the fluidity of milk for efficient secretion from the mammary gland. Conversion of 18:0 to cis-9 18:1 is the predominant precursor:product of the $\Delta-9$ desaturase complex, and results in about $40 \%$ of $18: 0$ taken up by the mammary gland being converted to cis-9 18:1, whilst conversion of 16:0 is much lower at circa $8 \%$ (Chilliard et al., 2000). The action of $\Delta-9$ desaturase in the bovine mammary gland is not confined to 16:0 and 18:0 fatty acids, and other SFA including 10:0, 12:0, 14:0, 17:0 also serve as substrates.

\section{Lipid metabolism in the rumen}

Even though ruminant diets contain predominantly unsaturated fatty acids, ruminant meat and milk contain much higher levels of SFA due in part to extensive biohydrogenation of dietary unsaturated fatty acids in the rumen. It is generally considered that rumen bacteria rather than protozoa are responsible for biohydrogenation (Harfoot \& Hazlewood, 1997) which serves to reduce the toxic effects of unsaturated fatty acids on bacterial growth (Palmquist et al., 2005; Wąsowska et al., 2006). 
Following ingestion plant lipids become released from structural components through mastication and microbial digestive processes, and hydrolysed by microbial lipases. The rate of hydrolysis is inversely related to melting point (Palmquist et al., 2005). Following lipolysis NEFA are released into the rumen and adsorbed onto feed particles and hydrogenated or directly incorporated into bacterial lipids. Numerous in vitro and in vivo studies have elucidated the major pathways of ruminal biohydrogenation (Harfoot \& Hazlewood, 1997). Metabolism of 18:2 n-6 and 18:3n-3 is considered to involve at least two distinct populations of ruminal bacteria which under normal conditions proceed via isomerisation of the cis-12 double bond resulting in the formation of conjugated 18:2 or 18:3, respectively. Conjugated intermediates are transient and are subsequently reduced to $18: 0$ as the final end product with trans-11 18:1 as a common metabolite intermediate (Figure 1).

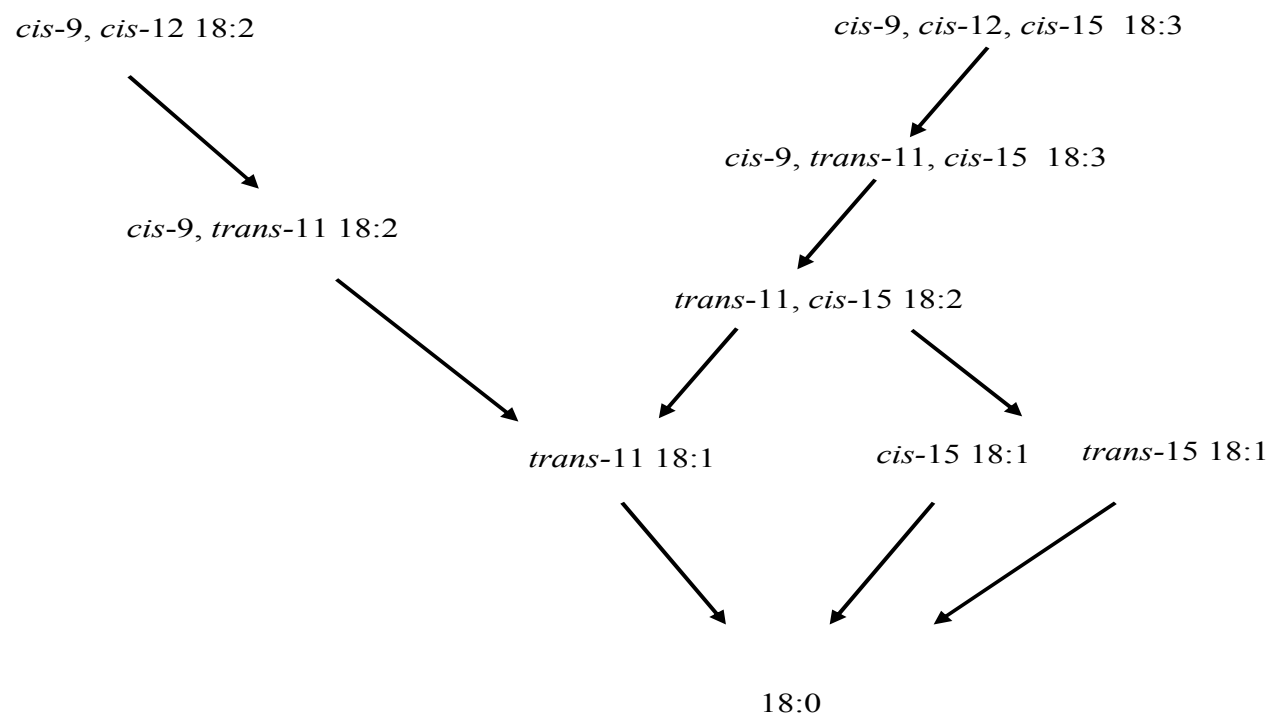

Figure 1. Major pathways of linoleic and linolenic acid metabolism in the rumen (adapted from Harfoot \& Hazlewood, 1997).

The final reduction step is considered to be rate limiting and therefore trans 18:1 intermediates can accumulate (Harfoot \& Hazlewood, 1997; Griinari \& Bauman, 1999). More recent studies have shown that biohydrogenation of dietary PUFA is more diverse than previously thought and a wide range of fatty acid intermediates are formed in the rumen and incorporated into milk fat (Palmquist et al., 2005; Shingfield et al., 2008). Estimates reported in the literature suggest that on most diets ruminal metabolism of dietary 18:2 $n-6$ and 18:3 n-3 biohydrogenation varies between $70-95 \%$ and $85-100 \%$, respectively (Doreau \& Ferlay, 1994). Similarly, 20:5 n-3 and 22:6 n-3 are extensively metabolized in rumen ca. 9095\% (Shingfield et al., 2003).

The composition of the diet, amount and type of lipid supplements and interactions between these factors are known to alter the predominant ruminal biohydrogention pathways resulting in changes in the profile of fatty acids available for absorption and incorporation into milk fat (Shingfield \& Griinari, 2007). A detailed appraisal on the impact of nutrition on ruminal lipid metabolism (Palmquist et al., 2005) concluded that i) ruminal biohydrogenation of dietary PUFA is most extensive on low concentrate diets based on ensiled forages, ii) incomplete metabolism of dietary PUFA to 18:0 leading to the accumulation of trans 18:1 intermediates occurs on diets containing high proportions of rapidly fermented carbohydrates, low amounts of fibre and/or plant oils or oilseeds, iii) fish oil or marine lipids rich in 20:5 n-3 and 22:6 n-3 are more potent inhibitors of the reduction of trans 18:1 intermediates to 18:0 in the rumen than plant oils and oilseeds, iv) isolated changes in the composition of the basal ration typically have minor effects on ruminal lipid metabolism, and iv) simultaneous alterations in the carbohydrate 
composition and lipid content of the diet have marked effects on the supply of ruminal biohydrogenation intermediates available for absorption.

\section{Effect of nutrition on milk fatty acid composition}

Nutrition is the major environmental factor regulating milk fat composition stimulating an extensive number of reviews on the effect of ruminant diet on milk fatty acid composition (Chilliard et al., 2000; Lock \& Shingfield, 2004; Dewhurst et al., 2006; Givens \& Shingfield, 2006; Shingfield et al., 2008). In the following section, the impact of oil supplements on milk fat composition is considered. A more detailed appraisal of the role of forages and concentrate supplements in the diet has been provided elsewhere (Dewhurst et al., 2006; Shingfield et al., 2008).

Supplementing the diet with plant oils or oilseeds is an effective means to decrease the concentration of medium-chain SFA in bovine milk (Table 1). For example, supplementing the diet with $50 \mathrm{~g} / \mathrm{kg}$ dry matter of linseed oil was shown to reduce the sum of 10:0 to $16: 0$ from 56 to $29 \mathrm{~g} / 100 \mathrm{~g}$ fatty acids (Roy et al., 2006). Reductions in medium-chain fatty acids to plant lipids are also accompanied by increases in milk fat 18:0 and cis-9 18:1 content due to i) increases in the amount of 18:0 available for absorption arising from extensive metabolism of unsaturated fatty acids in the rumen (Doreau \& Ferlay, 1994), ii) increases in the flow of cis-9 18:1 derived from oil supplements leaving the rumen and iii) conversion of 18:0 to cis-9 18:1 via $\Delta 9$-desaturase activity in the mammary gland. Since PUFA are not synthesized by ruminant tissues, the concentration of $n-6$ and $n-3$ in milk is dependent on the amounts of these fatty acids absorbed and partitioned towards the mammary gland. The supply of PUFA available for absorption is determined by both the amounts of PUFA in the diet and the extent of their metabolism in the rumen. Changes in milk fatty acid composition to plant or marine lipid supplements are dependent on i) the amount of oil included in the diet, ii) fatty acid profile of the lipid supplement, iii) form of lipid supplement and iv) composition of the basal diet. Attempts to enhance the concentration of a specific fatty acid in milk invariably results in changes in other fatty acids. For example, use of plant oils or oilseeds to decrease milk fat SFA and enhance milk cis-9 18:1, 18:2 n-6, CLA or 18:3 n-3 concentrations results in an inevitable increase in TFA content (Table 1).

Partially hydrogenated vegetable oils and ruminant-derived foods are the main sources of TFA in the human diet. Ruminant derived foods typically contain 1-8 \% of total fatty acids as TFA, with trans-11 18:1 being quantitatively the most important in ruminant milk on most diets (Bauman et al., 2005; Shingfield et al., 2008). The isomeric profile of partially hydrogenated oils typically follows a Gaussian distribution resulting in trans-9, $-10,-11$ and -12 as the main positional 18:1 isomers (Bauman et al., 2008). Further research is required to evaluate the effects of specific TFA isomers to substantiate the relative risks on cardio-vascular disease associated with trans fat consumption from industrial or ruminant sources.

\section{Conclusions}

Concerns on role of the human diet on the development of chronic diseases can be expected to continue in the future. In order to reduce the social and financial burden of chronic disease and extend life expectancy, there is increased interest in changing the composition of the diet for the maintenance of human health and disease prevention. Milk and dairy products are a significant source of fat and SFA in most Western diets. It is possible to significantly reduce the saturate content and enhance the concentration of several bioactive lipids several-fold in milk through changes in the ruminant diet. Most strategies involve supplementing the diet with plant oils or oilseeds, which due to the metabolism of dietary lipids in the rumen also results in an unavoidable increase in milk TFA content. A high consumption of TFA is associated with increased cardiovascular disease risk. However the profile of TFA in ruminant derived foods and processed edible fats differs markedly, with evidence from clinical and biomedical models to suggest that the physiological effects are isomer dependent. Overall, studies in human volunteers and animal models suggest that reductions in milk 12:0, 14:0 and 16:0 content and increases in milk fat cis-9 18:1, cis-9, trans-11 conjugated linoleic acid and 18:3n-3 has the potential to improve long-term human health. 
Table 1. Effect of plant oils and oilseeds on the fatty acid composition of bovine milk.

\begin{tabular}{|c|c|c|c|c|c|c|c|c|c|c|c|c|c|c|c|c|c|}
\hline \multirow[t]{2}{*}{ Lipid source } & \multirow{2}{*}{$\begin{array}{l}\text { Intake }^{1} \\
(\mathrm{~g} / \mathrm{d})\end{array}$} & \multirow[t]{2}{*}{ Forage $^{2}$} & \multirow[t]{2}{*}{$\mathrm{F}: \mathrm{C}^{3}$} & \multicolumn{14}{|c|}{ Milk fatty acid composition (g/100g total fatty acids) } \\
\hline & & & & $4: 0$ & $6: 0$ & $8: 0$ & $10: 0$ & $12: 0$ & $14: 0$ & $16: 0$ & $18: 0$ & $\begin{array}{l}\text { cis-9 } \\
18: 1\end{array}$ & $\begin{array}{c}\text { trans } \\
18: 1\end{array}$ & $\Sigma 18: 1$ & $18: 2 n-6$ & $18: 3 n-3$ & CLA \\
\hline Control & 0 & GS & $50: 50$ & 2.9 & 2.5 & 1.6 & 3.7 & 4.2 & 12.5 & 30.1 & 11.2 & 19.4 & 1.6 & 21.7 & 1.3 & 0.40 & 0.46 \\
\hline Rapeseed oil & 500 & & & 2.6 & 1.9 & 1.2 & 2.5 & 2.7 & 10.1 & 22.6 & 14.3 & 25.8 & 4.3 & 31.4 & 1.4 & 0.50 & 1.02 \\
\hline Control & 0 & MS/GS & $57: 43$ & 5.0 & 2.3 & 1.3 & 3.1 & 4.0 & 11.6 & 30.7 & 8.3 & 18.1 & 2.0 & 20.1 & 2.1 & 0.45 & 0.60 \\
\hline Cracked rapeseed & 2530 & & & 3.2 & 1.1 & 0.6 & 1.3 & 1.9 & 7.9 & 19.8 & 14.1 & 34.7 & 2.6 & 37.3 & 2.4 & 0.48 & 1.02 \\
\hline Cracked rapeseed $^{1}$ & 4100 & & & 2.7 & 1.0 & 0.4 & 1.0 & 1.4 & 6.0 & 18.0 & 15.8 & 39.3 & 2.0 & 41.3 & 2.8 & 0.60 & 0.74 \\
\hline Control & 0 & Hay & $59: 41$ & 3.5 & 2.5 & 1.6 & 4.1 & 5.1 & 13.5 & 35.1 & 6.1 & 13.4 & 2.2 & 15.6 & 2.0 & 0.79 & 0.58 \\
\hline Ground rapeseed & 920 & & & 3.4 & 2.6 & 1.6 & 3.7 & 4.3 & 12.8 & 27.7 & 10.3 & 19.5 & 4.0 & 23.5 & 1.8 & 0.79 & 0.70 \\
\hline Ground sunflowerseed & 950 & & & 3.5 & 2.5 & 1.7 & 3.5 & 4.1 & 12.3 & 28.3 & 9.9 & 18.9 & 4.8 & 23.6 & 2.5 & 0.79 & 0.93 \\
\hline Ground linseed & 1240 & & & 3.7 & 2.5 & 1.5 & 3.2 & 3.4 & 11.1 & 24.9 & 12.1 & 20.1 & 5.14 & 25.2 & 1.8 & 1.81 & 0.93 \\
\hline Control & & Pasture & $5^{4}$ & NR & 1.5 & 0.9 & 2.0 & 2.4 & 9.6 & 24.3 & 11.9 & 22.9 & 4.1 & 27.5 & 1.6 & 0.71 & $1.26^{5}$ \\
\hline Soyabean oil & 500 & & & NR & 1.1 & 0.5 & 1.2 & 1.6 & 7.1 & 20.5 & 12.5 & 27.0 & 6.9 & 35.0 & 1.9 & 0.67 & $1.93^{5}$ \\
\hline Control & 0 & $\mathrm{LH} / \mathrm{MS}$ & $50: 50$ & 3.9 & 2.5 & 1.5 & 3.5 & 4.0 & 12.1 & 29.4 & 10.4 & 16.1 & 1.8 & 18.3 & 2.6 & 0.54 & 0.40 \\
\hline Extruded soyabean $^{1}$ & 2415 & & & 3.9 & 2.3 & 1.3 & 2.8 & 3.0 & 10.1 & 24.0 & 12.1 & 18.9 & 3.8 & 23.1 & 4.5 & 0.87 & 0.87 \\
\hline Control & 0 & $\mathrm{MS} / \mathrm{GH}$ & $48: 52$ & 3.3 & 2.7 & 1.5 & 3.5 & 3.9 & 12.1 & 32.3 & 8.6 & 16.6 & 2.8 & 20.3 & 2.2 & 0.21 & 0.55 \\
\hline Sunflower oil & 957 & & & 2.3 & 1.2 & 0.5 & 1.2 & 1.6 & 7.1 & 18.9 & 13.6 & 28.3 & 11.5 & 41.0 & 2.3 & 0.20 & 0.93 \\
\hline Control & 0 & MS & $27: 73$ & 3.3 & 2.7 & 1.6 & 4.3 & 5.1 & 12.8 & 28.7 & 5.8 & 14.9 & 5.2 & 20.8 & 3.0 & 0.09 & 0.60 \\
\hline Sunflower oil & 755 & & & 1.8 & 1.0 & 0.5 & 1.2 & 1.8 & 7.4 & 19.1 & 6.3 & 19.4 & 23.7 & 52.0 & 4.6 & 0.15 & 1.17 \\
\hline Control $^{6}$ & 0 & $\mathrm{BS} / \mathrm{LS} / \mathrm{LH}$ & $60: 40$ & 4.1 & 2.4 & 1.2 & 2.5 & 2.9 & 11.6 & 30.6 & 9.8 & 17.7 & 4.6 & 23.5 & 1.7 & 0.41 & 0.68 \\
\hline Safflower oil $^{6}$ & 1125 & & & 2.8 & 1.4 & 0.6 & 1.3 & 1.5 & 8.1 & 18.7 & 11.4 & 17.7 & 17.6 & 38.5 & 2.9 & 0.32 & 4.12 \\
\hline Linseed oil ${ }^{6}$ & 1066 & & & 3.2 & 1.6 & 0.7 & 1.4 & 1.6 & 8.5 & 17.9 & 11.1 & 19.2 & 14.3 & 36.6 & 2.0 & 0.73 & 2.80 \\
\hline Control & 0 & GS & $60: 40$ & 1.8 & 1.0 & 0.6 & 1.8 & 2.7 & 9.9 & 40.2 & 12.3 & $\mathrm{NR}$ & 1.1 & 21.0 & 2.0 & 0.72 & 0.16 \\
\hline Linseed oil & 250 & & & 1.8 & 1.0 & 0.6 & 1.5 & 2.1 & 8.8 & 34.0 & 15.6 & $\mathrm{NR}$ & 2.1 & 27.2 & 1.8 & 0.84 & 0.28 \\
\hline Control & 0 & GH & $64: 36$ & 3.0 & 2.3 & 1.4 & 3.5 & 4.2 & 13.1 & 34.9 & 7.0 & 14.2 & 2.1 & 16.8 & 1.6 & 0.74 & 0.54 \\
\hline Linseed oil & 1050 & & & 2.8 & 1.8 & 0.8 & 1.8 & 2.0 & 8.3 & 17.1 & 12.8 & 20.6 & 12.2 & 33.7 & 1.2 & 0.74 & 2.89 \\
\hline Control & 0 & $\mathrm{GH}$ & $35: 65$ & 3.3 & 2.6 & 1.7 & 3.9 & 4.4 & 11.6 & 25.7 & 6.2 & 14.9 & 5.0 & 23.3 & 2.5 & 0.76 & 0.81 \\
\hline Linseed oil & 612 & & & 3.0 & 1.6 & 1.0 & 2.4 & 2.8 & 8.8 & 18.7 & 8.1 & 14.4 & 12.1 & 28.8 & 2.3 & 1.59 & 2.54 \\
\hline Control & 0 & MS/GS & $52: 48$ & 3.9 & 2.3 & 1.6 & 3.0 & 3.7 & 11.3 & 28.9 & 10.2 & 21.4 & 2.9 & 25.8 & 2.2 & 0.32 & 0.51 \\
\hline Crushed linseed $^{1}$ & 1500 & & & 3.9 & 2.0 & 1.3 & 2.4 & 2.9 & 9.9 & 23.9 & 12.6 & 26.1 & 3.4 & 31.2 & 2.8 & 0.87 & 0.62 \\
\hline Control & 0 & GS/MS & $64: 36$ & 2.8 & 2.4 & 1.3 & 3.0 & 4.2 & 11.8 & 31.7 & 11.4 & NR & 2.3 & 23.5 & 2.0 & 0.4 & 0.9 \\
\hline Ground raw linseed ${ }^{1}$ & 1975 & & & 2.5 & 1.8 & 0.9 & 1.7 & 2.2 & 7.8 & 20.4 & 19.9 & NR & 4.3 & 34.4 & 2.7 & 1.3 & 1.4 \\
\hline Micronised linseed $^{1}$ & 1930 & & & 2.5 & 1.9 & 1.0 & 2.0 & 2.6 & 8.3 & 21.7 & 18.3 & NR & 4.2 & 33.1 & 2.9 & 1.3 & 1.4 \\
\hline Extruded linseed ${ }^{1}$ & 1968 & & & 2.2 & 1.6 & 0.8 & 1.5 & 2.1 & 8.0 & 21.0 & 16.5 & NR & 5.9 & 37.4 & 3.1 & 0.7 & 1.9 \\
\hline
\end{tabular}

${ }^{1}$ Oil content (g/kg) of rapeseed, soyabean, crushed linseed and linseed, 480, 190, 280 and ca. 300, respectively. ${ }^{2}$ BS, barley silage; GH, grass hay; GS, grass silage; LH, lucerne hay; LS, lucerne silage; MS, maize silage. ${ }^{3}$ Forage:concentrate ratio of the diet (on a dry matter basis). ${ }^{4}$ Concentrate intake (kg/day). ${ }^{5}$ Total CLA content. In all other cases CLA refers to the concentration of cis-9, trans-11 CLA. ${ }^{6}$ Fatty acid concentrations reported as g/100 g fatty acid methyl esters. NR: not reported. Data derived from Shingfield et al., 2008. 


\section{References:}

Bauman, D.E., Lock, A.L., Corl, B.A., Ip, C., Salter, A.M., \& Parodi, P.M. 2005. Milk fatty acids and human health: Potential role of conjugated linoleic acid and trans fatty acids. In: Serjrsen, K., Hvelplund, T., \& Nielsen, M.O. (Eds.); Ruminant Physiology: Digestion, Metabolism and Impact of Nutrition on Gene Expression, Immunology and Stress, pp. 529-561. Wageningen, The Netherlands:Wageningen Academic Publishers.

Chilliard, Y., Ferlay, A., Mansbridge, R. M., \& Doreau, M. 2000. Ruminant milk fat plasticity: nutritional control of saturated, polyunsaturated, trans and conjugated fatty acids. Ann. Zootech. 49: 181205.

Dewhurst, R.J., Shingfield, K.J., Lee, M.R.F., \& Scollan, N.D. 2006. Increasing the concentrations of beneficial polyunsaturated fatty acids in milk produced by dairy cows in high-forage systems. Anim. Feed Sci. Technol. 131: 168-206.

Doreau, M., \& Ferlay, A. 1994. Digestion and utilisation of fatty acids by ruminants. Anim. Feed Sci. Technol. 45: 379-396.

Givens, D.I., \& Shingfield, K.J. 2006. Optimising dairy milk fatty acid composition. In: Williams, C., \& Buttriss, J. (Eds.); Improving the fat content of foods, pp. 252-280. Cambridge, UK:Woodhead Publishing Ltd.

Griinari, J.M., \& Bauman, D.E. 1999. Biosynthesis of conjugated linoleic acid and its incorporation into meat and milk in ruminants. In: Yurawecz, M.P., Mossoba, M.M., Kramer, J.K.G., Pariza, M.W., \& Nelson, G. (Eds.); Advances in Conjugated Linoleic Acid Research, pp. 180-200. Champaign, Illinois:AOCS Press.

Harfoot, C. G., \& Hazlewood, G. P. 1997. Lipid metabolism in the rumen. In: Hobson, P.N., \& Stewart', C.S. (Eds.), The rumen microbial ecosystem, second edition, pp. 382-426. London, UK:Blackie Academic \& Professional.

Jensen, R.G. 2002. The composition of bovine milk lipids: January 1995 to December 2000. J. Dairy Sci. 85: 295-350.

Lock, A.L., \& Shingfield, K.J. 2004. Optimising milk composition. In: Kebreab, E., Mills, J., \& Beever, D.E, (Eds.); UK Dairying: Using Science to Meet Consumers' Needs, pp. 107-188. Nottingham, UK:Nottingham University Press.

Korhonen, H. J. T., \& Pihlanto, A. 2006. Bioactive peptides: production and functionality. Int. Dairy J. 16: 945-960.

Palmquist, D. 1976. A kinetic concept of lipid transport in ruminants. A review. J. Dairy Sci. 59: $355-363$. Palmquist, D. L., Lock, A. L., Shingfield, K. J., \& Bauman, D. E. 2005. Biosynthesis of conjugated linoleic acid in ruminants and humans. In: Taylor, S.L. (Ed.); Advances in Food and Nutrition Research, Vol. 50, pp. 179-217. San Diego, California:Elsevier Academic Press.

Parodi, P. W. 2001. Cows' milk components with anti-cancer potential. Aus. J. Dairy Technol. 56: 65-73.

Roy, A., Ferlay, A., Shingfield, K.J., \& Chilliard, Y. 2006. Examination of the persistency of milk fatty acid composition responses to plant oils in cows given different basal diets, with particular emphasis on trans-C18:1 fatty acids and isomers of conjugated linoleic acid. Anim. Sci. 82: 479-492.

Shingfield, K.J., Ahvenjärvi, S., Toivonen, V., Ärölä, A., Nurmela, K.V.V., Huhtanen, P., \& Griinari, J.M. 2003. Effect of fish oil on biohydrogenation of fatty acids and milk fatty acid content in cows. Anim. Sci. 77: 165-179.

Shingfield, K.J., Chilliard, Y., Toivonen, V., Kairenius, P. \& Givens, D.I. 2008. Trans fatty acids and bioactive lipids in ruminant milk. In Bösze, Z. (Ed.); Bioactive components of milk, Advances in Experimental and Medical Biology, in press.

Shingfield, K.J., \& Griinari, J.M. 2007. Role of biohydrogenation intermediates in milk fat depression. Eur. J. Lipid Sci. Technol. 109: 799-816.

Wąsowska, I., Maia, M., Niedźwiedzka, K. M., Czauderna, M., Ramalho Ribeiro J. M. C., Devillard, E., Shingfield, K. J., \& Wallace, R. J. (2006). Influence of fish oil on ruminal biohydrogenation of C18 unsaturated fatty acids. Br. J. Nutr. 95: 1199-1211. 